\title{
TECHNOLOGY-ENABLED SERVICES: IMPORTANCE AND ROLE OF TECHNOLOGY READINESS
}

\author{
YING WANG* AND BEVERLEY SPARKS $†$ \\ *Department of Tourism, Sport, and Hotel Management, Gold Coast Campus, \\ Griffith University, Queensland, Australia \\ †Centre for Tourism, Sport and Services Research, Griffith Business School, \\ Griffith University, Queensland, Australia
}

\begin{abstract}
Set in the tourism/hospitality context, this study explores consumer perceptions of technologyenabled services (TESs) and their relationship to technology readiness (TR). Data were collected through a web-based survey from air travelers and hotel patrons. The results suggest that customers generally separate TESs into three categories: peripheral, standard, and network access related, with standard TESs being most important. The perceived importance of TESs is found to be positively associated with consumers' technology readiness, and the strength of this association is stronger in the airline case, suggesting a moderation effect of service category on the relationship between perceived importance of TESs and TR. The findings of this study should help organizations make technology-related decisions and develop the right technological infrastructure for achieving competitiveness and customer satisfaction.
\end{abstract}

Key words: Technology-enabled services (TESs); Technology readiness (TR); Hotel; Airline

\section{Introduction}

Acceleration of technological developments has changed the service environment dramatically, presenting opportunities and challenges to both service firms and customers. One response of service firms has been to introduce an array of technologyenabled services (TESs), including mature services of online booking and self-check-in at airports, and emerging services such as mobile-based reservation system and complementary use of an iPad in hotels. Many firms attempt to compete by expanding the range of TESs. However, customers may not value the added TESs, which can also increase operating costs, especially for services with high customer support and logistics needs (Boyer, Hallowell, \& Roth, 2002). For TESs to be a valuable asset and an effective competitive strategy, firms must consider customer needs and perceptions. Nevertheless, research efforts on TESs are still disproportionally limited to the increasing availability of these services (Beatson, Coote, \& Rudd, 2006; 
Gelderman, Ghijsen, \& van Diemen, 2011; J-S. C. Lin \& Hsieh, 2007; Meuter, Ostrom, Roundtree, \& Bitner, 2000). In addition, most prior research focuses on a single TES, which fails to inform how customers make choices between TESs (Liljander, Gillberg, Gummerus, \& van Riel, 2006; Meuter et al., 2000).

A problem with TESs is that availability does not necessarily lead to use, especially when customers find them unfamiliar or difficult to comprehend (Liljander et al., 2006). An important challenge for service firms, then, is persuading customers to use TESs (Gelderman et al., 2011). Since personal differences and traits influence consumer attitudes and behaviors toward TESs, a useful measure would assess technology readiness (TR), which reflects a person's tendency to embrace new technologies and related perceptions or behaviors (Parasuraman, 2000; Parasuraman \& Colby, 2001). TR influences customers' use and evaluation of TESs (Gelderman et al., 2011; J-S. C. Lin \& Hsieh, 2007; Meuter, Ostrom, Bitner, \& Roundtree, 2003). As a personal trait (C-H. Lin, Shih, \& Sher, 2007), TR may be influenced by situational factors in its behavioral expression (Weiten, 2004). As firms become more reliant on TESs in service delivery, customer TR should be of both academic and managerial concern.

In response to the need for more research on TESs, this study, set in the tourism/hospitality sector, explores consumer perceptions of TESs and their relationship to TR. The study addresses the following research questions in an airline and hotel context:

- What TESs are important to customers in their decision to purchase a service?

- Does TR influence customers' perceived importance of TESs?

- Does TR's influence vary across service categories?

This study contributes to the literature of TESs and TR in general and to that of tourism and hospitality in particular. First, it demonstrates that TR is likely to positively affect customers' perceived importance of a wide range of TESs implemented by airlines and hotels, adding to the knowledge of TR's relationship to customer attitude toward TESs. Second, it is the first study to investigate TR's influence across service categories, providing empirical evidence to confirm the moderation effect of service categories and the situational nature of the role TR plays. Third, it extends the limited TR research into the tourism and hospitality settings, where technologies are used widely in service delivery and business understanding of technology consumption is paramount.

\section{Literature Review}

\section{Technology-Enabled Services}

Airlines and hotels have implemented a multitude of TESs in service delivery. Some TESs, such as online booking and self-check-in kiosks, are selfservice technologies operated by customers. Other TESs such as hotel automatic greeting systems that create personalized greetings are operated by staff and are aimed at enhancing the customer experience. As used in this study, the term TES includes both categories of services.

Previous classification studies on self-service technologies are often conceptual and normative in nature, and they are built primarily on a service provider's standpoint (Cunningham, Young, \& Gerlach, 2008). These studies are cross-industry, resulting in classifications based on criteria such as customization, standardization, and separability (e.g., Cunningham et al., 2008; Meuter et al., 2000). However, TESs available within a particular industry may exhibit similarities in these criteria.

A useful way to differentiate between TESs is by linking them to the technology life cycle, including the stages of introduction, growth, maturity, and decline, through which a particular technology progresses (Rogers, 1995). In the 1960s, hotel guests paid extra to have a color television in their rooms, a new technology at the time but a standard attribute of today's accommodation product. Similarly, airlines' own websites and their presence on thirdparty booking sites have transformed from new and peripheral services to dominant flight booking channels for travelers (International Air Transport Association [IATA], 2011a).

\section{Technology Readiness}

In his seminal work, Parasuraman (2000) proposes the TR construct, which measures consumers' 
propensity to embrace and interact with new technologies. TR is a state of mind shaped by mental enablers (optimism and innovativeness) and inhibitors (discomfort and insecurity) that collectively determine a person's tendency to use technology. TR is by far the most integrative measure of the propensity to embrace technology (Yi, Tung, \& Wu, 2003), whereas other measures, such as personal innovativeness and technology anxiety, capture only part of the domain of TR. As Parasuraman (2000) points out, the influence of customers' overall TR and individual TR dimensions are both worthy topics for research. The measurement of TR can be through an extensive 36-item measure (Parasuraman, 2000) or by a shorter 10 -item measure such as that reported by Victorino, Karniouchina, and Verma (2009).

TR can positively affect consumer perceptions of the usefulness and ease of use of an e-service, leading to positive attitudes and behavior toward the service (C-H. Lin et al., 2007; Parasuraman, 2000). It affects consumer perceptions of and intentions to use e-service (C-H. Lin et al., 2007), and as consumer TR increases, purchase intention on a hotel website increases correspondingly (Ranaweera, Bansal, \& McDougall, 2008). Liljander et al. (2006) also find that TR plays a positive, albeit minor, role in explaining consumer attitude toward the use and evaluation of airline self-check-in features. People who are technologically savvy are more likely to gather information to evaluate whether technologies can be trusted (Mahmood, Bagchi, \& Ford, 2004). By extension, customers with higher levels of TR may be more willing to spend time exploring TES options and obtain more benefits from these services. Consequently, they should place more importance on TESs than customers with lower TR levels. In other words, the more ready a customer is for new technologies, the more he or she perceives TESs as important service attributes when choosing a service provider. We therefore propose that

H1: TR is positively associated with the perceived importance of TESs.

\section{Moderation Effect of Service Category}

As personal traits, TR dimensions are individual specific and reflect general beliefs in technologies (C-H. Lin et al., 2007). Personal traits are relatively stable descriptors of individuals and are invariant across circumstances (Walczuch, Lemmink, \& Streukens, 2007; Weiten, 2004). However, the behavioral expression of a personal trait is characterized by situational specificity rather than absolute consistency (Mischel, 1973). Skinner (1974) holds that behavior is fully determined by environmental stimuli, and that personality is a collection of response tendencies tied to various stimulus situations. Bandura (1986), in contrast, believes that personality is developed through learning, and his social cognitive theory suggests a "triadic reciprocality" where the person, the environment, and behavior all influence one another to form a system of reflexive determination. As a result, people evaluate the circumstance and respond with adjusted behavior, and they may express a specific trait more easily in some situations than others (Kenrick \& Funder, 1991, cited in Weiten, 2004). Based on these, a reasonable assumption is that the impact of TR on TES-related perception and behavior varies in different circumstances. For instance, a complex interaction effect exists of TR, site type, and access method on customer evaluation of online service interfaces (Massey, Khatri, \& MontoyaWeiss, 2007). Compared to higher TR explorers, the lower TR segment of skeptics evaluated utilitarian web interfaces as significantly more important than hedonic ones in terms of ease of use.

The empirical context of this study includes the airline and hotel sectors, the two largest components of the tourism industry. Airlines rely on technologies to serve passengers before, during, and after their flying experiences and to reinforce the airline brand (Buhalis, 2003). Technologies have driven down costs while providing convenience and improved quality and revenue. According to the International Air Transport Association (IATA, 2011b), e-ticketing has reduced the processing cost from US $\$ 10$ to US $\$ 1$ per passenger and has achieved $\$ 3$ billion in annual savings.

Hotels began adopting hospitality industry-specific technologies in the early 1970s and have become increasingly dependent on technology-based solutions (Cobanoglu, Berezina, Kasavana, \& Erdem, 2011). Technologies have been applied in guest-room services and at the managerial and service operational levels (S.-C. Lee, Barker, \& Kandampully, 2003). Hotels have also shifted toward technology-based 
marketing and customer retention, applying developments in social media (C. C. Lee \& Hu, 2004). In general, hotels seem to lack recognition of technologies' full potential (S.-C. Lee et al., 2003) and have been slow to implement the latest guest-room technologies (Beldona \& Cobanoglu, 2007). This delay may be attributable to the traditional view that information technology and service are incompatible concepts (Law, Leung, \& Buhalis, 2009), or to the perception that these technologies cannot directly improve productivity and revenue (Ham, Kim, \& Jeong, 2005).

Hotel stays are usually relaxing experiences, and in hotels, TESs are generally easier to operate and employee support is accessible. In contrast, many people find air travel to be a stressful experience (Martinussen, Gundersen, \& Pedersen, 2011; McIntosh, Swanson, Power, Raeside, \& Dempster, 1998), and air travelers' level of stress and anxiety is exacerbated by encounters with TESs such as reduced human contact at check-in (Martinussen et al., 2011). People's abilities to withstand stress vary. Optimistic people, who expect good outcomes, can cope with stressful situations in more adaptive ways and are more likely to focus on positive aspects of the experience (Weiten, 2004). We expect a stronger association between TR and perceived importance of TESs in the case of air travel because a technologically sophisticated service environment requires customers to be technology ready, and because higher TR customers are more optimistic about technologies, they are more capable of dealing with a technology-related stressful event than are those who are less technology ready. In short, airlines and hotels present different levels of innovation in employing TESs, and customers in the two sectors experience varying levels of stress and anxiety. We therefore propose that

H2: Service category (i.e., airline vs. hotel) moderates the association between TR and the perceived importance of TESs.

\section{Method}

\section{Survey Instrument}

To collect data for the study, we developed a questionnaire including measures of TR, assessments of perceived importance of TESs, and respondents' social demographic characteristics.

\section{Measures of TR}

Following Parasuraman and Colby (2001), Victorino et al. (2009) used an abbreviated 10-item TR scale. The instrument has been shown to be a reliable measure in the hospitality context (Victorino et al., 2009), and is adopted in this study (see the Appendix). Respondents were asked to indicate their levels of agreement with each of the 10 items on 7-point Likert type scales ranging from 1 (strongly disagree) to 7 (strongly agree).

\section{Measures of Perceived Importance of TESs}

Respondents rated the importance of various TESs to their selection of service provider when booking a flight or hotel stay on 7-point Likert type scales ( 1 = not at all important, 7 = very important $)$. As technologies implemented by airlines differ from those provided by hotels, separate lists of TESs were developed for the two service categories. We drew the initial lists from a review of literature, e-mediated chat rooms, and industry and newspaper reports. The lists were then evaluated by top managers of four airlines and six hotels in Australia, who provided their opinions on the availability of TESs (if unavailable, the intention to adopt) and the importance of these TESs to customer satisfaction. The final lists included 35 airline and 38 hotel TESs. Respondents indicated whether they knew about each of the TESs and were not required to rate the importance of TESs that they were not familiar with.

\section{Procedure}

We incorporated a pilot test in the study to evaluate the general design of the questionnaire, test the reliability and validity of the TR scale, ensure accuracy, and remove ambiguities in the questionnaire wording. A pilot questionnaire was placed on a website reputable for hosting research surveys, and it collected responses from a sample of 133 participants at an Australian university, on the basis of which we revised the questionnaire, making minor changes to item and question wording.

Data for the main study, which also used a webbased survey, were collected in Australia. Access to potential respondents was provided by a reputable marketing-list company that assisted in obtaining a quota sample based on criteria set by the researchers 
to seek a balance across genders and the different Australian states and territories. Only people who were 18 or older and had recently stayed in a hotel or taken a flight were included in the sample frame. Invitation e-mails with the survey link embedded were forwarded to potential respondents by the marketing-list company on behalf of the researchers, and an information sheet was supplied at the beginning of the survey for respondents to make an informed decision on whether to partake in the study. Respondents who stayed at a hotel answered the hotel TES list, and air travelers rated the airline TESs.

\section{Results}

\section{Sample}

A quota sample of 368 participants completed the survey, with 192 responding to questions about the airline sector and 176 responding to questions about the hotel sector. As Table 1 shows, the sample was reasonably well distributed across gender (53\% male), age (32.9\% under 35 years, 37.8\% between 36 and 55 years, and $29.3 \%$ older than 55 years), and household income (21.2\% below $\$ 40,000$, $47.9 \%$ between $\$ 60,001$ and $\$ 100,000$, and $30.9 \%$ above \$150,000). All respondents had stayed in a hotel/taken a flight within the past 12 months, with the majority of their experience within 3 months of the survey (69.0\% and 70.3\% for airline and hotel, respectively).

\section{Factor Analysis Results}

A factor analysis using principal axis extraction and oblimin rotation with Kaiser normalization reduced airline TESs to three general factors, explaining $63.9 \%$ of the variance in the data. We excluded several items from the analysis because of low communality, cross-loading problems, or failure to load on any factor. In the airline case, items include in-cabin electrical outlet at each seat, flight booking kiosk in the airport, personal permanent electric bag tag, business center in the airport, additional fee-paying entertainment, and staff-operated check-in station. Deleted hotel TESs include wake-up call system, presence on major booking websites, in-room electronic safety box, self-check-in, self-check-out, central reservation number, remote control TV, and plasma screen TV.
Table 1

Sample Profile

\begin{tabular}{|c|c|c|}
\hline Variables & $n$ & $\%$ \\
\hline \multicolumn{3}{|l|}{ Gender $(N=367)$} \\
\hline Male & 196 & 53.4 \\
\hline Female & 171 & 46.6 \\
\hline \multicolumn{3}{|l|}{ Age $(N=359)$} \\
\hline Under 25 years & 42 & 11.7 \\
\hline $26-35$ years & 76 & 21.2 \\
\hline $36-45$ years & 68 & 18.9 \\
\hline $46-55$ years & 68 & 18.9 \\
\hline $56-65$ years & 71 & 19.8 \\
\hline$>65$ years & 34 & 9.5 \\
\hline \multicolumn{3}{|l|}{ Highest qualification $(N=365)$} \\
\hline Completed year 10 or less & 37 & 10.1 \\
\hline Completed year 11 or 12 & 66 & 18.1 \\
\hline College certificate or diploma & 63 & 17.3 \\
\hline Trade qualification & 31 & 8.5 \\
\hline Undergraduate degree & 97 & 26.6 \\
\hline Postgraduate degree & 71 & 19.5 \\
\hline \multicolumn{3}{|l|}{ Gross household income $(N=359)$} \\
\hline$\$ 40,000$ or less & 76 & 21.2 \\
\hline$\$ 40,001-60,000$ & 72 & 20.1 \\
\hline$\$ 60,001-80,000$ & 49 & 13.6 \\
\hline$\$ 80,001-100,000$ & 51 & 14.2 \\
\hline$\$ 100,001-150,000$ & 63 & 17.5 \\
\hline Greater than $\$ 150,000$ & 48 & 13.4 \\
\hline \multicolumn{3}{|l|}{ Relationship status $(N=364)$} \\
\hline Single & 86 & 23.6 \\
\hline Married/de facto relationship & 250 & 68.7 \\
\hline Separated/divorced/widowed & 28 & 7.7 \\
\hline \multicolumn{3}{|l|}{ Service category $(N=368)$} \\
\hline Airline & 176 & 47.8 \\
\hline Hotel & 192 & 52.2 \\
\hline
\end{tabular}

Based on the highest loading items (Field, 2009; Thompson, 2004), the factors were named "Peripheral TESs," "Standard TESs," and "Network Access" (see Table 2). "Peripheral TESs" include predominantly newly introduced TESs that are largely peripheral rather than core functional attributes of the booking and flight/hotel stay experience. "Standard TESs" are relatively more established TESs that are core functional attributes of the booking and flight/hotel stay experience. "Network Access" refers to TESs that provide or facilitate network access.

We examined factorability and sampling adequacy by checking the correlation matrixes, Bartlett's test of sphericity statistics $(p<0.01)$, Kaiser-Meyer-Olkin $(\mathrm{KMO})$ test statistics $(\mathrm{KMO}$ test statistic $=0.942)$, and anti-image correlation matrixes, which raised no concern. 
Table 2

Factor Solution for Airline TESs

\begin{tabular}{|c|c|c|c|c|c|c|}
\hline \multirow{2}{*}{\multicolumn{2}{|c|}{ TES Item }} & \multicolumn{3}{|c|}{ Factor } & \multirow[b]{2}{*}{ Mean } & \multirow[b]{2}{*}{ Rank } \\
\hline & & 1 & 2 & 3 & & \\
\hline \multicolumn{2}{|l|}{ SMS boarding pass } & 0.815 & & & 4.56 & 23 \\
\hline \multicolumn{2}{|c|}{ In-flight long-distance videoconference calls } & 0.812 & & & 3.58 & 29 \\
\hline \multicolumn{2}{|l|}{ Mobile/Smartphone check-in } & 0.789 & & & 4.83 & 20 \\
\hline \multicolumn{2}{|l|}{ Presence on social media } & 0.765 & & & 3.61 & 28 \\
\hline \multicolumn{2}{|c|}{ Flight-booking facility on board } & 0.703 & & & 4.42 & $25 / 26$ \\
\hline \multicolumn{2}{|c|}{ Mobile/WAP-based reservation systems } & 0.619 & & & 4.52 & 24 \\
\hline \multicolumn{2}{|c|}{ Automatic boarding gate } & 0.567 & & & 5.08 & 15 \\
\hline \multicolumn{2}{|c|}{ In-flight long-distance telephone calls } & 0.560 & & & 4.25 & 27 \\
\hline \multicolumn{2}{|c|}{ USB port at each seat } & 0.502 & & & & \\
\hline \multicolumn{2}{|c|}{ Wireless apps for mobile device systems } & 0.496 & & & 4.62 & 22 \\
\hline \multicolumn{2}{|c|}{$\begin{array}{l}\text { Touch-screen kiosk for feedback and complaint } \\
\text { in the airport }\end{array}$} & 0.404 & & & 5.01 & 16 \\
\hline \multicolumn{2}{|c|}{ Online booking capability } & & 0.863 & & 6.15 & 2 \\
\hline \multicolumn{2}{|c|}{ Web check-in/print-at-home boarding pass } & & 0.822 & & 5.90 & 3 \\
\hline \multicolumn{2}{|c|}{ E-mail boarding pass } & & 0.715 & & 5.64 & 5 \\
\hline \multicolumn{2}{|l|}{ Individual airline website } & & 0.661 & & 5.86 & 4 \\
\hline \multicolumn{2}{|l|}{ Free in-flight entertainment } & & 0.644 & & 6.20 & 1 \\
\hline \multicolumn{2}{|l|}{ Central reservation number } & & 0.562 & & 5.51 & 7 \\
\hline \multicolumn{2}{|l|}{ E-mail contact } & & 0.552 & & 5.45 & 10 \\
\hline \multicolumn{2}{|c|}{ Express check-in/self-check-in kiosks } & & 0.541 & & 5.60 & 6 \\
\hline \multicolumn{2}{|c|}{ Baggage tracking kiosk } & & 0.526 & & 5.46 & 9 \\
\hline \multicolumn{2}{|c|}{ Presence on major booking websites } & & 0.508 & & 5.35 & 12 \\
\hline \multicolumn{2}{|c|}{ Loyalty card check-in } & & 0.503 & & 5.27 & $13 / 14$ \\
\hline directions of gate on mobile & \multicolumn{5}{|c|}{ Real-time update on flight status/baggage/ } & 11 \\
\hline Automatic baggage drop & & & 0.429 & & 5.27 & $13 / 14$ \\
\hline In-flight Wi-Fi intranet & & & & -0.969 & 4.86 & 18 \\
\hline In-flight wireless Internet a & & & & -0.905 & 4.84 & 19 \\
\hline In-flight Internet access & & & & -0.856 & 4.99 & 17 \\
\hline In-flight high-speed Intern & cess & & & -0.853 & 4.75 & 21 \\
\hline Wireless Internet access in & airport & & & -0.583 & 5.48 & 8 \\
\hline Factor & Composite Mean & $\begin{aligned} \mathrm{Va} \\
\mathrm{Exp}\end{aligned}$ & & Cront & 's $\alpha$ & \\
\hline Factor 1: Peripheral & 4.4129 & 50 & & & & \\
\hline Factor 2: Standard & 5.4406 & & & & & \\
\hline Factor 3: Network Access & 4.9437 & & & & & \\
\hline Overall & 5.0029 & 63 & & & & \\
\hline
\end{tabular}

Note: Loadings less than 0.4 are not shown.

Factor analysis of hotel TESs obtained a similar solution, with three factors labeled as "Peripheral TESs," "Network Access," and "Standard TESs" (see Table 3). The solution explains $59.575 \%$ of the variance $(\mathrm{KMO}$ test statistic $=0.928, p<0.01)$. We performed Cronbach's alpha test for internal consistency of the measurement on each factor and the entire scale. As Tables 2 and 3 show, all alpha values exceeded the suggested cutoff of 0.70 (Hair, Black, Babin, Anderson, \& Tatham, 2006).
The far right column in Table 2 and Table 3 provides details of the ranks of the importance of each TES. Free in-flight entertainment, online booking capability, web check-in, individual airline websites, and e-mail boarding pass are the five most important TESs to air travelers, whereas the bottom five services include in-flight long-distance videoconference calls, presence on social media, inflight long-distance telephone calls, flight-booking facility on-board, and USB port at seat. For hotel 
Table 3

Factor Solution for Hotel TESs

\begin{tabular}{|c|c|c|c|c|c|c|}
\hline \multirow{2}{*}{\multicolumn{2}{|c|}{ TES Item }} & \multicolumn{3}{|c|}{ Factor } & \multirow[b]{2}{*}{ Mean } & \multirow[b]{2}{*}{ Rank } \\
\hline & & 1 & 2 & 3 & & \\
\hline \multicolumn{2}{|c|}{ Automatic customer greeting system } & 0.839 & & & 4.04 & 29 \\
\hline \multicolumn{2}{|c|}{ Videoconferencing capability } & 0.838 & & & 4.15 & 27 \\
\hline \multicolumn{2}{|l|}{ Web TV } & 0.828 & & & 4.24 & 25 \\
\hline \multicolumn{2}{|l|}{ Electronic meal ordering } & 0.820 & & & 4.22 & 26 \\
\hline \multicolumn{2}{|c|}{ Portable or speaker phone in room } & 0.804 & & & 4.45 & 21 \\
\hline \multicolumn{2}{|l|}{ In-room business service } & 0.787 & & & 4.15 & 28 \\
\hline \multicolumn{2}{|l|}{ Presence on social media } & 0.769 & & & 3.75 & 30 \\
\hline \multicolumn{2}{|c|}{ In-room/on-demand personal computer } & 0.765 & & & 4.52 & 18 \\
\hline \multicolumn{2}{|c|}{ Touch-screen kiosk for feedback and complaint } & 0.746 & & & 4.48 & 20 \\
\hline \multicolumn{2}{|l|}{ Complimentary use of iPad } & 0.745 & & & 4.26 & 24 \\
\hline \multicolumn{2}{|l|}{ Voice mail } & 0.726 & & & 4.56 & 17 \\
\hline \multicolumn{2}{|c|}{ Wireless point-of-sale system } & 0.718 & & & 4.67 & 14 \\
\hline \multicolumn{2}{|c|}{ Additional data line accessible to desk } & 0.715 & & & 4.68 & 13 \\
\hline \multicolumn{2}{|c|}{ Business centers } & 0.708 & & & 4.81 & 12 \\
\hline \multicolumn{2}{|l|}{ Pay-per-view } & 0.707 & & & 4.34 & 23 \\
\hline \multicolumn{2}{|c|}{ Wireless apps for mobile device systems } & 0.700 & & & 4.64 & 15 \\
\hline \multicolumn{2}{|c|}{$\begin{array}{l}\text { TV-based services (e.g., TV checkout and TV } \\
\text { meal ordering) }\end{array}$} & 0.696 & & & 4.61 & 16 \\
\hline \multicolumn{2}{|c|}{ Mobile/WAP-based reservation systems } & 0.682 & & & 4.50 & 19 \\
\hline \multicolumn{2}{|c|}{ Vending machine for beverage and confectionery } & 0.662 & & & 4.39 & 22 \\
\hline \multicolumn{2}{|c|}{$\begin{array}{l}\text { Other electronic entertainment systems (e.g. DVD } \\
\text { and mini-HiFi) }\end{array}$} & 0.609 & & & 5.05 & 10 \\
\hline \multicolumn{2}{|c|}{ Free long-distance telephone calls } & 0.543 & & & 4.95 & 11 \\
\hline \multicolumn{2}{|c|}{ Wireless Internet access in common areas } & & 0.842 & & 5.75 & 7 \\
\hline \multicolumn{2}{|c|}{ Wireless Internet access in room } & & 0.792 & & 5.81 & 5 \\
\hline High-speed Internet access & ommon areas & & 0.757 & & 5.80 & 6 \\
\hline E-mail contact & & & 0.534 & & 5.72 & 8 \\
\hline Online reservation capabil & n own website & & 0.510 & & 5.89 & 4 \\
\hline Easily accessible electrical & lets & & 0.449 & & 6.05 & $2 / 3$ \\
\hline In-room temperature contr & & & & 0.778 & 6.29 & 1 \\
\hline Electronic door locking sys & Electronic key cards & & & 0.721 & 5.70 & 9 \\
\hline Hotel's own website & & & & 0.696 & 6.05 & $2 / 3$ \\
\hline Factor & Composite Mean & $\begin{array}{r}\mathrm{Va} \\
\mathrm{Ex}]\end{array}$ & & $\mathrm{Cr}$ & I’s $\alpha$ & \\
\hline Factor 1: Peripheral & 4.4432 & & & & & \\
\hline Factor 2: Standard & 5.834 & & & & & \\
\hline Factor 3: Network Access & 6.0069 & & & & & \\
\hline Overall & 5.0220 & & & & & \\
\hline
\end{tabular}

Note: Loadings less than 0.4 are not shown.

patrons, the most important TESs are in-room temperature control, hotel's own website, easily accessible electrical outlets, online reservation capacity on own website, and wireless Internet access in room. TESs ranked in the bottom five include presence on social media, automatic customer greeting system, in-room business services, videoconferencing capacity, and electronic meal ordering. In both the airline and hotel cases, the most important TESs loaded primarily on the Standard TESs factor, and the least important TESs loaded on the Peripheral TESs factor.

Table 2 and Table 3 also display the composite means of the factors. We first obtained factor means by averaging the scores of all items loading on the factors for each respondent, and then calculated the composite means by averaging factor mean scores of all respondents. A series of paired-samples $t$ test results suggest that the factor means are statistically different from each other $(p<0.01)$. Standard TESs 
Table 4

Correlations by Service Categories

\begin{tabular}{lcccr}
\hline Variable Pairs & $\begin{array}{c}R \text { (Hotel) } \\
(N=192)\end{array}$ & $\begin{array}{c}R \text { (Airline) } \\
(N=174)\end{array}$ & Difference & $t$ Value \\
\hline 1. TR and peripheral TESs & 0.106 & $0.394^{*}$ & -0.288 & $3.188^{*}$ \\
2. TR and standard TESs & $0.271^{*}$ & $0.465^{*}$ & -0.194 & $3.773^{*}$ \\
3. TR and network access-related TESs & 0.048 & $0.450^{*}$ & -0.402 & $4.341^{*}$ \\
\hline
\end{tabular}

${ }^{*} p<0.01$.

and Peripheral TESs have the highest and lowest means for both airline and hotel. We then used factor means in subsequent analysis of TR's influence on perceived importance of TESs.

\section{Correlation and Hierarchical \\ Regression Analyses Results}

We calculated a composite variable measuring overall TR as the mean of the 10 items in the abbreviated TR scale (items measuring discomfort and insecurity were reverse coded), a common method for calculating composite measures suggested by Hair et al. (2006). The Cronbach's alpha coefficient of 0.772 indicates the reliability of the measurement. We then performed correlation analysis and independent samples $t$ test to examine TR's relationship to age and gender. The results suggest that TR does not vary as a result of age ( $R=0.099$, $p>0.05$ ) or gender ( $t$ value $=0.943, p>0.05$ ). There is no significant difference in TR between the airline (4.563) and hotel (4.521) samples $(t=0.454$, $p>0.05)$.

Correlation analysis can be used to detect a moderating effect when the moderator is a dichotomy and the moderating effect is measured by comparing the correlation coefficients of the subgroups (Baron \& Kenny, 1986). Table 4 shows that all the correlation coefficients are significant in the airline sample, but the correlation is only significant between TR and standard TESs in the hotel sample, meaning that TR's influence may only exist for standard TESs in the hotel case. The two sets of coefficients are significantly different $(p<0.01)$, suggesting a possible moderating effect of service category.

We then tested the moderating effect using hierarchical regression analysis and established three regression models for each type of TESs (see
Table 5). The first model (models 1.1, 2.1, and 3.1) includes the main effect of TR on perceived importance of TESs. The second model (models 1.2, 2.2, and 3.2) includes an additional effect of the moderator, service category, which has two levels for airline and hotel, coded as 0 and 1, respectively. In model three (models 1.3, 2.3, and 3.3), the interactive term (the product of the independent and moderator variables) representing the moderating effect is included. If the interactive term is significant, the moderator hypothesis is supported. The independent variable, the moderator, and the interactive term are entered in different steps to investigate the increase in the variance accounted for by each new variable entered into the model (Ro, 2012; Ryu \& Han, 2010). We used the centered TR variable in modeling to reduce multicollinearity.

Table 6 shows that all models on the whole are significant $(p<0.01)$. The $\beta_{1}$ coefficient is significant in models $1.1,2.1$, and $3.1(p<0.01)$, suggesting a main effect of TR on the perceived importance of the three types of TESs. In other words, TR is

Table 5

Regression Models

\begin{tabular}{|c|c|}
\hline Models & \\
\hline 1.1 & IMP_Peripheral $=\beta_{0}+\beta \mathrm{TR}+\varepsilon$ \\
\hline 1.2 & $\begin{array}{l}\text { IMP_Peripheral }=\beta_{0}+\beta_{1}^{1} \text { TR }+ \\
\beta_{2} \text { Air/Hotel }+\varepsilon\end{array}$ \\
\hline 1.3 & $\begin{array}{l}\text { IMP_Peripheral }=\beta_{0}+\beta_{1} \text { TR }+\beta_{2} \text { Air } / \text { Hotel }+ \\
\beta_{3^{*}}\left(\text { TR }{ }_{*} \text { Air } / \text { Hotel }\right)+\varepsilon\end{array}$ \\
\hline 2.1 & IMP_Standard $=\beta_{0}+\beta_{1} \mathrm{TR}+\varepsilon$ \\
\hline 2.2 & IMP_Standard $=\beta_{0}+\beta_{1}$ TR $+\beta_{2}$ Air $/$ Hotel $+\varepsilon$ \\
\hline 2.3 & $\begin{array}{l}\text { IMP_Standard }=\beta_{0}+\beta_{1}^{1} \text { TR }+\beta_{2}^{2} \text { Air/Hotel }+ \\
\beta_{3^{*}}\left(\text { TR }{ }_{*} \text { Air } / \text { Hotel }\right)+\varepsilon\end{array}$ \\
\hline 3.1 & IMP_Network Access $=\beta_{0}+\beta_{1} \mathrm{TR}+\varepsilon$ \\
\hline 3.2 & $\begin{array}{l}\text { IMP_Network Access }=\beta_{0}+\beta_{1}^{1} \text { TR }+ \\
\beta_{2} \text { Air } / \text { Hotel }+\varepsilon\end{array}$ \\
\hline 3.3 & $\begin{array}{l}\text { IMP_Network Access }=\beta_{0}+\beta_{1} \text { TR }+\beta_{2} \text { Air } / \text { Hotel }+ \\
\beta_{3^{*}}\left(\mathrm{TR}{ }_{*} \text { Air/Hotel }\right)+\varepsilon\end{array}$ \\
\hline
\end{tabular}


Table 6

Results of Regression Analysis

\begin{tabular}{|c|c|c|c|c|c|c|c|}
\hline Type of TESs/Model & Variable & B & $\begin{array}{c}\text { Standardized } \\
\beta\end{array}$ & $t$ & Sig. & $R^{2} /$ Adjusted $R^{2}$ & $\begin{array}{c}R^{2} \\
\text { Change }\end{array}$ \\
\hline \multicolumn{8}{|l|}{ Peripheral TESs } \\
\hline 1.1 & $\mathrm{TR}$ & $0.368 * *$ & $0.246 * *$ & 4.844 & 0.000 & $\begin{array}{l}0.061 / 0.058 \\
F(1,364)=23.462 * *\end{array}$ & \\
\hline \multirow[t]{2}{*}{1.2} & TR & $0.368^{* *}$ & $0.246^{* *}$ & 4.837 & 0.000 & $0.061 / 0.55$ & \multirow{5}{*}{$0.027^{* *}$} \\
\hline & Air/Hotel & 0.008 & 0.003 & 0.063 & 0.950 & $F(2,363)=11.701^{* *}$ & \\
\hline \multirow[t]{3}{*}{1.3} & TR & $0.639 * *$ & $0.427 * *$ & 5.696 & 0.000 & $0.087 / 0.080$ & \\
\hline & Air/Hotel & 0.010 & 0.004 & 0.076 & 0.940 & $F(3,362)=11.524 * *$ & \\
\hline & TR ${ }_{*}$ Air/Hotel & $-0.491 * *$ & $-0.243 * *$ & -3.249 & 0.001 & & \\
\hline \multicolumn{8}{|l|}{ Standard TESs } \\
\hline 2.1 & TR & $0.403^{* *}$ & $0.353 * *$ & 7.195 & 0.000 & $\begin{array}{l}0.124 / 0.122 \\
F(1,364)=51.762 * *\end{array}$ & \multirow{6}{*}{$0.010^{*}$} \\
\hline \multirow[t]{2}{*}{2.2} & TR & $0.406^{* *}$ & $0.356 * *$ & 7.336 & 0.000 & $0.145 / 0.140$ & \\
\hline & Air/Hotel & $0.284^{* *}$ & $0.142 * *$ & 2.921 & 0.004 & $F(2,363)=30.683^{* *}$ & \\
\hline \multirow[t]{3}{*}{2.3} & $\mathrm{TR}$ & $0.531 * *$ & $0.466^{* *}$ & 6.461 & 0.000 & $0.154 / 0.147$ & \\
\hline & Air/Hotel & $0.285^{* *}$ & $0.142 * *$ & 2.941 & 0.003 & $F(3,362)=22.034^{* *}$ & \\
\hline \multirow{2}{*}{\multicolumn{8}{|c|}{ Network access-related TESs }} \\
\hline & & & & & & & \\
\hline 3.1 & $\mathrm{TR}$ & $0.363^{* *}$ & $0.299 * *$ & 4.494 & 0.000 & \multicolumn{2}{|l|}{$\begin{array}{l}0.053 / 0.050 \\
F(1,364)=20.197 * *\end{array}$} \\
\hline \multirow[t]{2}{*}{3.2} & TR & $0.379 * *$ & $0.240 * *$ & 5.230 & 0.000 & $0.239 / 0.235$ & \multirow{5}{*}{$0.052 * *$} \\
\hline & Air/Hotel & $1.200^{* *}$ & $0.432 * *$ & 9.425 & 0.000 & $F(2,363)=56.954^{* *}$ & \\
\hline \multirow[t]{3}{*}{3.3} & TR & $0.777 * *$ & $0.491 * *$ & 7.430 & 0.000 & \multirow{3}{*}{$\begin{array}{l}0.290 / 0.284 \\
F(2,363)=49.374^{* *}\end{array}$} & \\
\hline & Air/Hotel & $1.202^{* *}$ & $0.433 * *$ & 9.766 & 0.000 & & \\
\hline & TR ${ }_{*}$ Air/Hotel & $-0.722 * *$ & $-0.338 * *$ & -5.127 & 0.000 & & \\
\hline
\end{tabular}

${ }^{*} p<0.05,{ }^{* *} p<0.01$

significantly associated with the perception of TESs and customers with higher TR scores considered TESs more important. Therefore, $\mathrm{H} 1$ is supported.

The $\beta_{3}$ coefficients in models $1.3,2.3$, and 3.3 are all significant, indicating that service category (airline or hotel) acted as a moderator of TR's influence on perceived importance of TESs. The improvement of $R^{2}$ owing to the addition of the interactive term is statistically significant in models $1.3\left(\Delta R^{2}=0.027, p<0.01\right), 2.3\left(\Delta R^{2}=0.010\right.$, $p<0.05)$, and $3.3\left(\Delta R^{2}=0.052, p<0.01\right)$. Therefore, $\mathrm{H} 2$ is supported. The $\beta_{3}$ coefficients are negative, meaning that the moderating effect decreases as the service category goes from airline (0) to hotel (1). In other words, TR's influence is stronger in the airline sample than in the hotel sample. From the results presented in Figures 1-3, the existence of a moderating effect is also graphically evident.

\section{Discussion}

Focusing on airline and hotel services, this research examined the impact of TR and service category on the importance of TES attributes perceived by customers.

What TESs Are Important to Customers in Their Decision to Purchase a Service?

As this study shows, all TESs, except one for hotels and two for airlines, received an importance score greater than 4 (the neutral point), indicating TESs as important criteria that customers use to evaluate hotel and airline products. Three dimensions of TESs emerged from the factor analysis, including "Standard," "Network Access," and "Peripheral” TESs, in descending order of importance to both airline travelers and hotel customers. Prior research seems to suggest that the categorization of technologies by service employees is based on functionality (Ham et al., 2005). In contrast, in the current study customers differentiated new technologies from old technologies, highlighting the relevance of technology life cycle and consumer TR in managing TESs. The difference in perception between service firms and customers 


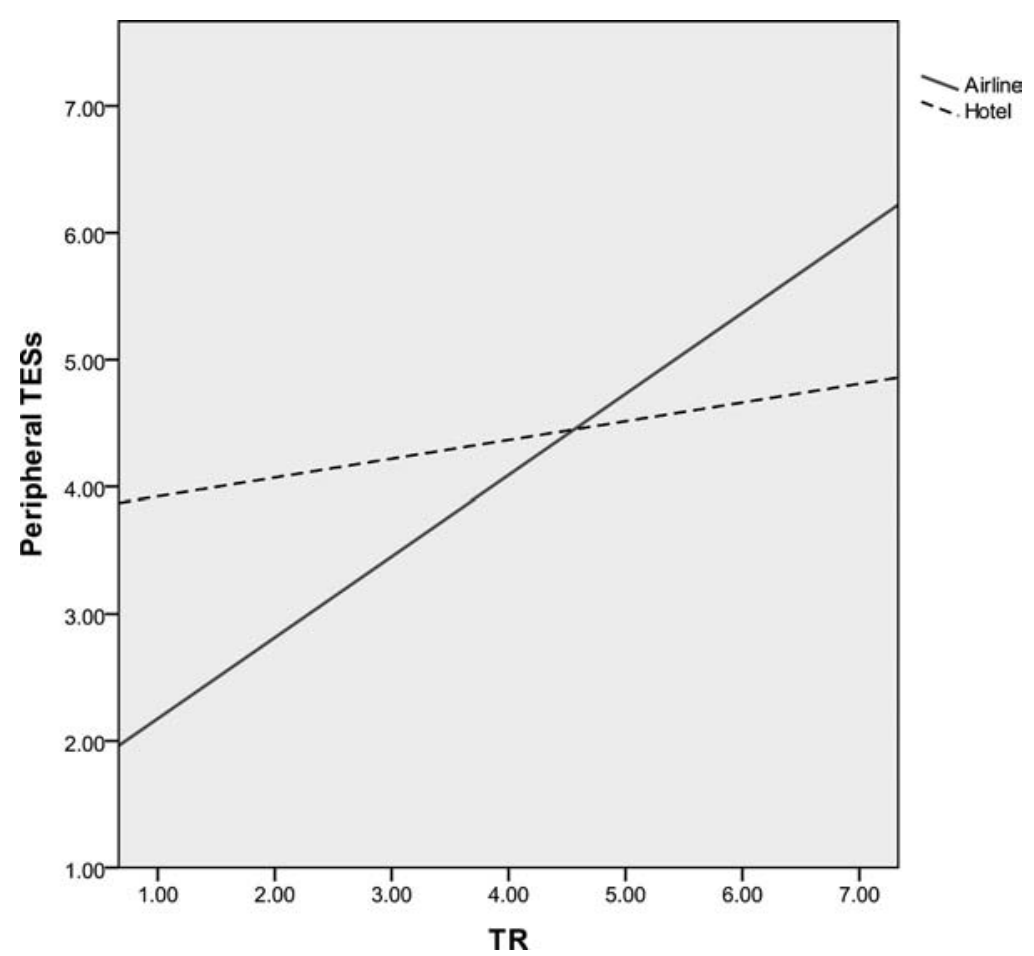

Figure 1. Moderating effect of service category on perceived importance of peripheral TESs.

may be related to firms' primary motivation of achieving productivity, effectiveness, and operability through technologies. As the technology adoption life cycle suggests, customers adopt TESs at different stages of their life cycle (Beldona \& Cobanoglu, 2007; Beldona, Nusair, \& Demicco, 2009). Airlines and hotels thus need to investigate whether the three categories of TESs attract different market segments. Profiling these segments facilitates personalization, customization, and customer interaction in the management and marketing of these services.

Standard TESs are highly important to customers and may be viewed as "must-have" attributes that customers expect from air and hotel services. However, hotels have not adopted as many technological advances (Beldona \& Cobanoglu, 2007). In line with this delay, this study found that hotel customers may expect a narrower range of musthave TESs than air travelers, which may imply a further means for hotels to differentiate from one another on the basis of TESs features. Although the Internet is another important criterion, especially in the hotel sample, that customers use in decision making, airlines and hotels in Australia do not often provide Internet access free of charge.

Perceived importance can affect customer expectations, engagement in information search, and performance evaluations. Customers who attach greater importance to a purchase spend more time in information search and have more explicit expectations from the product. Their zone of tolerance for service performance also varies depending on the importance of service attributes (Tam, 2011). Thus, airlines and hotels must actively look for ways to distribute information to customers regarding important TESs, as doing so would help build favorable attitudes toward the service provider, particularly among the more technologically savvy customers.

The result that respondents perceived Peripheral TESs as less important than the other two 


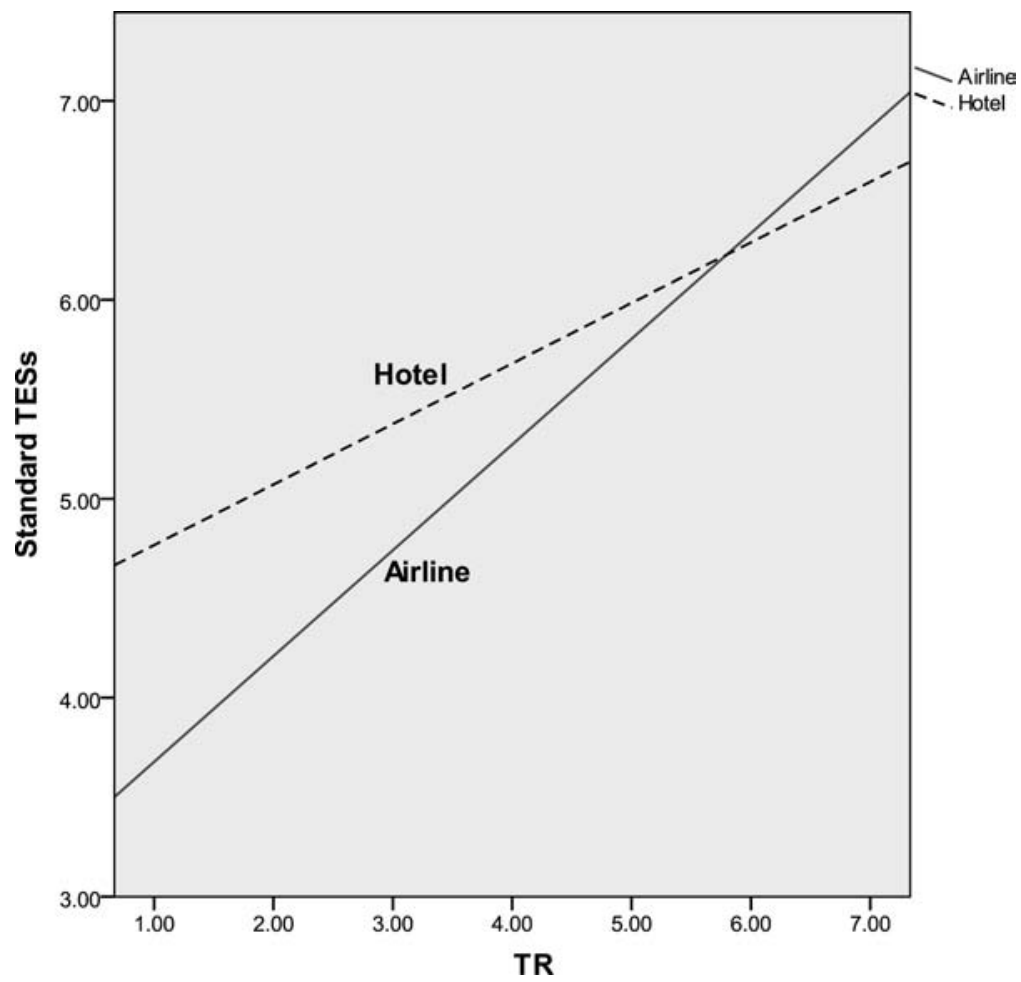

Figure 2. Moderating effect of service category on perceived importance of standard TESs.

dimensions might be associated with perceived risks and uncertainties related to new services, which in turn reduced the perceived value of these services. Customers engage more actively in TES encounters when they believe that employee support would become available if necessary (Anitsal \& Paige, 2006). To encourage positive attitudes and behaviors toward new TESs, firms must create a supporting environment with adequate service assistance available to customers at their convenience. New TESs may be classified as disruptive technologies, which have a tendency to evolve into mainstream technologies, leading to significant competitive advantages for innovative firms (Cobanoglu et al., 2011). Airlines and hotels should not automatically discount the value of these services. Rather, a program monitoring customers' actual use and evaluations of these TESs is needed to prepare for future service delivery. Nevertheless, because of their relatively low importance, resources and effort should not concentrate on these TESs to avoid possible overkills from a marketing perspective.

\section{Does TR Influence Customers' \\ Perceived Importance of TESs?}

The finding that TR is significantly associated with the perceived importance of TESs confirms that TR is a useful market segmentation variable for tourism businesses, in line with literature on TR and segmentation (Parasuraman \& Colby, 2001; Tsikriktsis, 2004; Victorino et al., 2009). Firms positioning themselves as leaders in technology-based service innovation can focus on higher TR segments.

Lower TR customers may have needs different from those who are more technologically savvy (Stockdale, 2007). They need more help and often feel uncomfortable with new technologies (Walczuch et al., 2007). Providing TES-related information, education, and support is thus particularly 


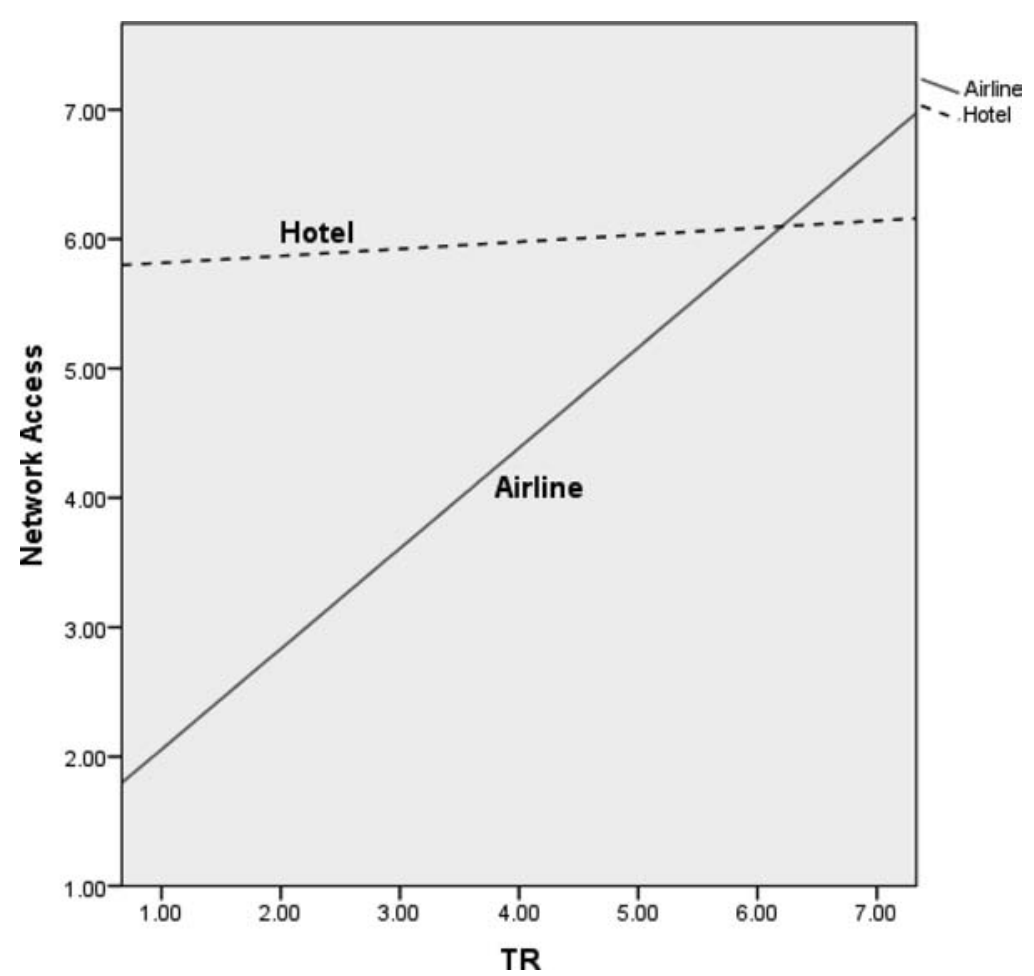

Figure 3. Moderating effect of service category on perceived importance of network access related TESs.

important for low-TR customers. To optimize the benefits of TES implementation, firms could identify strategies, such as a user-friendly interface and promotion of knowledge about TESs in marketing, to strengthen positive TR drivers (optimism and innovativeness) and reduce TR inhibitors (discomfort and insecurity). Marketing materials could be tailored to suit varied needs of customers at different levels of TR.

\section{Does TR's Influence Vary Across \\ Service Categories?}

The relationship between TR and the importance of TESs was stronger when decision making involved airline services. This result may be attributable to the more technologically advanced nature of airlines compared to hotels. Also, as a result of airlines' aggressive promotion of TESs, consumers have a greater awareness of airlines' relative merits in offering TESs. Those who are more technologically ready may also be more cognizant of technology innovations, have more experiences with TESs, and thus be more equipped to explore the benefits of these services. They therefore are likely to place greater importance on TESs. In comparison, many hotel TESs such as in-room amenities are easier to operate, and thus customer perceptions are less likely to be influenced by TR. In other words, the relationship between TR and perception may depend on the level of technology innovation by service firms in an industry. Consequently, aggregate analysis of or focus on just one service sector might be highly misleading.

The moderation effect of service category was particularly evident in the case of network access. The expectation of Internet access on planes is low; therefore, the perceived importance is low, with only the higher TR travelers demanding such services. In contrast, Internet access is commonly expected in hotels; hotels are often workplaces for business travelers and offer opportunities for leisure 
travelers to catch up on family news or search for things to do. Therefore, respondents placed a high importance on such services.

\section{Theoretical and Practical Implications}

Given the increasing reliance on TESs in service delivery, developing an in-depth understanding of customer attitudes toward these services is of paramount importance. This study contributes to both academia and practice. As acknowledged previously, research on TESs and the application of TR is lacking. Prior investigations have also generated conflicting results regarding TR's impact on consumer behavior. Responding to these issues, this study extended the limited TR research to tourism services by investigating TR's relationship to the importance of TESs when customers make purchase decisions. The findings of TR's significant association with perceived importance of TESs across all three types of TESs enrich the knowledge of TR and provide additional support for a positive impact of TR on consumer attitudes and behaviors toward TESs. By recognizing the contextual effect of service category, this study also contributes to the understanding of how TR can interact with situational factors to assert influence, an area in which prior research is limited. This contribution indicates that studies on TES provision in industries with high levels of technological innovation could incorporate TR as an explanatory variable of customer attitudes and behavior.

The practical implications from this research lead to several suggestions. First, the findings can help service providers identify mismatches between their TES provision and customer needs in service design, quality management, and marketing. For example, access to the Internet, identified as an important service attribute in the hotel group, is often offered at an additional cost. To attract customers, firms should provide these services free of charge (in the hotel case) or make them more cost-effective (in the airline case). Second, in light of the result that TR is significantly associated with how customers view TESs in decision making, businesses can incorporate customer TR as an important customer characteristic and a potential market segmentation variable. Third, although many TES features do not generate revenue directly, they may do so indirectly by influencing customers' purchase decision. Fourth, firms must establish programs to regularly monitor service quality and customer satisfaction related to TESs, especially standard TESs. Given the high importance consumers attach to these TESs, a negative experience could have a detrimental effect on customer satisfaction.

\section{Conclusions, Limitations, and Further Research}

This study focuses on TESs, an increasingly important mode of service delivery, and concludes that TESs, especially standard and Internet-related TESs, are key service attributes that may influence a customer's choice of service provider, making these services a significant focal point in the design and marketing of services. Customers who are more technologically ready consider TESs more important when making a purchase decision, indicating that TR is a useful variable for market segmentation, especially for service firms at the forefront of technological innovation. TR's role is contextual and is likely to be stronger in industries with high degrees of technological sophistication.

This study has limitations that point to several directions for further research. First, although 376 respondents constitute an adequate sample size for analysis, the airline and hotel samples are relatively small, and the respondents were drawn from a marketing list using a quota sampling method. The TESs lists compiled were based on Australian airlines and hotels and may not be generalizable to other countries where different selections of TESs are offered. Online data collection also excludes those who do not have Internet access. Thus, the results need to be validated in larger and more comprehensive samples, as well as in cross-cultural contexts.

Second, in cases related to Peripheral TESs the explanatory power of TR is low. In those cases, TR may have played a minor role in explaining the perceived importance of TESs. As Peripheral TESs are mainly characterized as new technologies, future studies could complement the TR scale with early adopter measures.

Third, the study did not consider situational and social factors other than service category that may 
affect the relationship between TR and the importance of TESs. For instance, familiarity with TESs is another influential situational factor and nationality may have an impact on what is important. Further research needs to measure customers' familiarity and prior experience with TESs, and differentiate between groups of customers according to their social demographics and travel behaviors.

Fourth, because of its exploratory nature, this study considered TR to be an overall measure of customer readiness for new technologies, without differentiating various dimensions of TR and their relative importance in influencing customers' view of TESs. Further research could investigate the role of individual TR dimensions and map how TR dimensions interact, not only with each other but also with moderators, to affect customer attitudes and behavior.

Finally, most studies so far have treated TR as a factor influencing customers' acceptance and adoption of TESs, which represent the first phase of user experience. More attention needs to be directed to TR's impact on the remaining phases of a consumption experience.

\section{Acknowledgments}

This study is funded under the Griffith University New Researcher Grants Scheme. We would also like to acknowledge the additional support provided by the Centre for Tourism, Sport and Services Research, Griffith Business School.

Appendix

10-Item TR Scale

Technology gives us more control over our daily lives.

I like the idea of doing business via computers because I am not limited to regular business hours.

Technology makes me more efficient in my occupation.

In general, I am among the first in my circle of friends to acquire new technology when it appears.

I can usually figure out new high-tech products and services without help from others.

When I get technical support from a provider of a high-tech product or service, I sometimes feel as if I am being taken advantage of by someone who knows more than I do.

New technology is often too complicated to be useful.

I do not consider it safe giving out a credit card number over a computer.

I do not feel confident doing business with a place that can only be reached online.

If I provide information to a machine or over the Internet, I can never be sure it really gets to the right place.

\section{References}

Anitsal, I., \& Paige, R. C. (2006). An exploratory study on consumer perceptions of service quality in technologybased self-service. Services Marketing Quarterly, 27(3), 53-67.

Bandura, A. (1986). Social foundations of thought and action: A social-cognitive theory. Englewood Cliff, NJ: Prentice-Hall.

Baron, R. M., \& Kenny, D. A. (1986). The moderator-mediator variable distinction in social psychological research: Conceptual, strategic, and statistical considerations. Journal of Personality and Social Psychology, 51(6), 1173-1182.

Beatson, A., Coote, L. V., \& Rudd, J. M. (2006). Determining consumer satisfaction and commitment through selfservice technology and personal service usage. Journal of Marketing Management, 22(7), 853-882.

Beldona, S., \& Cobanoglu, C. (2007). Importanceperformance analysis of guest technologies in the lodging industry. Cornell Hotel and Restaurant Administration Quarterly, 48(3), 299-312.

Beldona, S., Nusair, K., \& Demicco, F. (2009). Online travel purchase behaviour of generational cohorts: A longitudinal study. Journal of Hospitality Marketing and Management, 18(4), 406-420.

Boyer, K. K., Hallowell, R., \& Roth, A. V. (2002). E-services: Operating strategy-A case study and a method for analysing operational benefits. Journal of Operations Management, 20(2), 175-188.

Buhalis, D. (2003). eTourism: Information technology for strategic tourism management. London: Pearson Education.

Cobanoglu, C., Berezina, K., Kasavana, M. L., \& Erdem, M. (2011). The impact of technology amenities on hotel guest overall satisfaction. Journal of Quality Assurance in Hospitality and Tourism, 12(4), 272-288.

Cunningham, L. F., Young, C. E., \& Gerlach, J. H. (2008). Consumer views of self-service technologies. The Service Industries Journal, 28(6), 719-732.

Field, A. (2009). Discovering statistics using SPSS (3rd ed.). Thousand Oaks, CA: Sage Publications Inc.

Gelderman, C. J., Ghijsen, P. W. T., \& van Diemen, R. (2011). Choosing self-service technologies or interpersonal services-The impact of situational factors and technology-related attitudes. Journal of Retailing and Consumer Services, 18(5), 414-421. 
Hair, J. F., Black, W. C., Babin, B. J., Anderson, R. E., \& Tatham, R. L. (2006). Multivariate data analysis (6th ed.). Upper Saddle Rivers, NJ: Prentice Hall.

Ham, S., Kim, W. G., \& Jeong, S. (2005). Effect of information technology on performance in upscale hotels. International Journal of Hospitality Management, 24(2), 281-294.

International Air Transport Association. (2011a). Vision 2050. Retrieved from http://www.iata.org/pressroom/ facts_figures/Documents/vision-2050.pdf

International Air Transport Association. (2011b, December). Fact sheets: 100\% electronic ticketing. Retrieved January 2, 2012, from http://www.iata.org/pressroom/ facts_figures/fact_sheets/Pages/et.aspx

Law, R., Leung, R., \& Buhalis, D. (2009). Information technology applications in hospitality and tourism: A review of publications from 2005 to 2007. Journal of Travel and Tourism Marketing, 26(5-6), 599-623.

Lee, C. C., \& Hu, C. (2004). Analysing hotel customers' E-complaints from an Internet complaint forum. Journal of Travel and Tourism Marketing, 17(2/3), 167-181.

Lee, S.-C., Barker, S., \& Kandampully, J. (2003). Technology, service quality, and customer loyalty in hotels: Australian managerial perspectives. Managing Service Quality, 13(5), 423-432.

Liljander, V., Gillberg, F., Gummerus, J., \& van Riel, A. (2006). Technology readiness and the evaluation and adoption of self-service technologies. Journal of Retailing and Consumer Services, 13(3), 177-191.

Lin, C-H., Shih, H-Y., \& Sher, P. J. (2007). Integrating technology readiness into technology acceptance: The TRAM model. Psychology and Marketing, 24(7), 641-657.

Lin, J-S. C., \& Hsieh, P-L. (2007). The influence of technology readiness on satisfaction and behavioural intentions toward self-service technologies. Computers in Human Behaviour, 23(3), 1597-1615.

Mahmood, M. A., Bagchi, K., \& Ford, T. C. (2004). On-line shopping behaviour: cross-country empirical research. International Journal of Electronic Commerce, 9(1), 9-30.

Martinussen, M., Gundersen, E., \& Pedersen, R. (2011). Predicting fear of flying and positive emotions towards air travel. Aviation Psychology and Applied Factors, 1(2), 70-74.

Massey, A. P., Khatri, V., \& Montoya-Weiss, M. M. (2007). Usability of online services: The role of technology readiness and context. Decision Sciences, 38(2), 277-308.

McIntosh, I. B., Swanson, V., Power, K. G., Raeside, F., \& Dempster, C. (1998). Anxiety and health problems related to air travel. Journal of Travel Medicine, 5(4), 198-204.

Meuter, M. L., Ostrom, A. L., Bitner, M. J., \& Roundtree, R. (2003). The influence of technology anxiety on consumer use and experiences with self-service technologies. Journal of Business Research, 56(11), 899-906.

Meuter, M. L., Ostrom, A. L., Roundtree, R. I., \& Bitner, M. J. (2000). Self-service technologies: Understanding customer satisfaction with technology-based service encounters. Journal of Marketing, 64(3), 50-64.

Mischel, W. (1973). Toward a cognitive social learning conceptualisation of personality. Psychological Review, 80(4), 252-283.

Parasuraman, A. (2000). Technology Readiness Index (TRI): A multiple-item scale to measure readiness to embrace new technologies. Journal of Service Research, 2(4), 307-320.

Parasuraman, A., \& Colby, C. L. (2001). Techno-ready marketing: How and why our customers adopt technology. New York: Free Press.

Ranaweera, C., Bansal, H., \& McDougall, H. (2008). Web site satisfaction and purchase intention, impact of personality characteristics during initial web site visit. Managing Service Quality, 18(4), 329-348.

Rogers, E. M. (1995). Diffusion of innovations (4th ed.). New York: Free Press.

Ro, H. (2012). Moderator and mediator effects in hospitality research. International Journal of Hospitality Management, 31(3), 952-961.

Ryu, K., \& Han, H. (2010). Influence of the quality of food, service, and physical environment on customer satisfaction and behavioural intention in quick-casual restaurants: Moderating role of perceived price. Journal of Hospitality and Tourism Research, 34(3), 310-329.

Skinner, B. F. (1974). About behaviourism. New York: Knopf.

Stockdale, R. (2007). Managing customer relationships in the self-service environment of e-tourism. Journal of Vacation Marketing, 13(3), 205-219.

Tam, J. L. M. (2011). The moderating effects of purchase importance in customer satisfaction process: An empirical investigation. Journal of Consumer Behaviour, 10(4), 205-215.

Thompson, B. (2004). Exploratory and confirmatory factor analysis: Understanding concepts and applications. Washington, DC: American Psychological Association.

Tsikriktsis, N. (2004). A technology readiness-based taxonomy of customers, a replication and extension. Journal of Services Research, 7(1), 42-52.

Victorino, L., Karniouchina, E., \& Verma, R. (2009). Exploring the use of the abbreviated technology readiness index for hotel customer segmentation. Cornell Hospitality Quarterly, 50(3), 342-359.

Walczuch, R., Lemmink, J., \& Streukens, S. (2007). The effect of service employees' technology readiness on technology acceptance. Information and Management, 44(2), 206-215.

Weiten, W. (2004). Psychology: Themes and variations (6th ed.). Belmont, CA: Thomson.

Yi, Y., Tung, L. L., \& Wu, Z. (2003). Incorporating technology readiness (TR) into TAM: Are individual traits important to understand technology acceptance? DIGIT 2003 Proceedings, Paper 2. Retrieved December 9, 2011, from http://aisel.aisnet.org/cgi/viewcontent.cgi?article= 1001\&context=digit2003 